\title{
Tim Huijts
}

Utrecht University, The Netherlands

\section{Gerbert Kraaykamp}

Radboud University Nijmegen, The Netherlands

\section{Peer Scheepers}

Radboud University Nijmegen, The Netherlands

\begin{abstract}
We have examined the extent to which ethnic diversity in neighbourhoods and municipalities in The Netherlands is related to personal contact with neighbours from ethnic in-groups and out-groups among the native majority as well as among ethnic minorities. The results indicate that ethnic diversity is negatively related to personal contacts with native neighbours, but positively to personal contacts with neighbours from other ethnic groups. This applies equally to native respondents and Turks and Moroccans, rejecting Putnam's hunkering-down hypothesis and ethnic competition theory. Instead, ethnic diversity increases meeting opportunities with ethnic minorities while decreasing meeting opportunities with the native majority.
\end{abstract}

\section{Keywords}

ethnic diversity, ethnic minorities, multi-level models, neighbourhoods, social capital

\section{Introduction}

At the end of the twentieth century, Western European countries faced a considerable influx of immigrants from other continents (Castles and Miller, 2003). The rising levels of ethnic diversity that followed from these immigration flows have spurred strong debates. In several countries, political 
parties criticizing immigrant integration in the country of destination and favouring strict immigration laws have rapidly gained electoral support, reflecting the fact that many native inhabitants of Western Europe feel threatened in the presence of immigrants (Schneider, 2008; Semyonov et al., 2008).

As a result, increasing attention has been given to the consequences of ethnic diversity for Western societies. In his seminal article, Putnam (2007) argued that ethnic diversity erodes social solidarity and social cohesion. According to this argument, living in social contexts with high levels of ethnic diversity causes people to 'hunker down': they will pull in like a turtle. More specifically, this would mean that individuals in ethnically diverse settings are less trusting in others, engage less in social activities and social organizations, and have less personal contact with others (in other words, they have less social capital). Although Putnam focuses on the relationship between ethnic diversity and trust, his theoretical claim is that ethnic diversity erodes all forms of social capital. This would apply equally to private and public connections, to bonding social ties within one's own social group as well as to bridging social ties with other social groups, and to the ethnic majority and ethnic minority groups.

Putnam's article has spurred on a large number of scholars to test this argument. After all, his study still provided little empirical evidence for these theoretical claims and his analyses were limited to one country context (i.e. the United States). Moreover, Putnam's conclusions were based on models that were seriously limited in some respects, such as the control variables used to adjust for effects of neighbourhoods' level of ethnic diversity on social capital. Several studies based on other countries, multiple contextual levels (e.g. countries, regions, municipalities and neighbourhoods) and more adequate adjustments for confounding variables have been conducted. Most of these concluded that the detrimental influence of ethnic diversity on social capital is modest at most, if not absent (e.g. Bécares et al., 2011; Gesthuizen et al., 2009; Gijsberts et al., 2011; Hooghe et al., 2009; Letki, 2008; Tolsma et al., 2009). Hence, so far Putnam's core claims have found little support in recent empirical studies.

In the present study, we contribute to this strand of research by performing further rigorous tests of Putnam's hunkering-down hypothesis. In doing so, we focus on informal personal contacts with neighbours, since detrimental effects of ethnic diversity on informal social ties would reflect an even stronger confirmation of Putnam's hunkering-down hypothesis than the erosion of formal social capital. Although several shortcomings of Putnam's approach have been dealt with in previous research, the major lacuna of existing work in this field is that no explicit distinction was made between social capital within the own ethnic group, and social capital between different ethnic groups. Hence, our main research questions read: to what extent is living in neighbourhoods and municipalities in The Netherlands with different levels of ethnic diversity negatively related to informal personal contacts with (a) neighbours from the ethnic in-group and (b) neighbours from ethnic out-groups?, and, additionally, to what extent do these relationships differ between the native Dutch majority and ethnic minorities?

By focusing on The Netherlands, we provide a particularly strong test case of Putnam's hunkeringdown hypothesis. After all, the average level of informal social capital in The Netherlands is among the highest in Europe (Pichler and Wallace, 2007). Hence, the potential reduction of informal social capital due to high ethnic diversity is particularly large in The Netherlands. If no support for the hunkeringdown hypothesis is found in The Netherlands, it is even less likely to be found in other European countries. Additionally, variation in ethnic diversity between neighbourhoods and municipalities is strong in The Netherlands, but strong neighbourhood segregation is absent (Gijsberts et al., 2012). As a result, ethnic groups in The Netherlands interact socially, but the extent to which ethnic majority and minority groups are confronted with each other varies between localities.

Our approach is innovative in four respects. First, we combine the minority perspective (e.g. Vervoort et al., 2010) and the majority perspective (e.g. Tolsma et al., 2009) on the influence of ethnic diversity on informal social capital by comparing natives and ethnic minority groups to assess whether ethnic diversity has the same effects for all ethnic groups alike. In a recent study focusing on The Netherlands, Vervoort et al. (2010) found that living in neighbourhoods with high ethnic diversity increases social contacts with members of people's own ethnic group and other ethnic minority groups, but decreases social contacts with natives. However, Vervoort et al. (2010) only analysed individuals from ethnic 
minority groups. Given that these findings contradict Putnam's strict version of the 'hunkering-down' hypothesis for ethnic minority groups, the present study aims to examine whether this also holds for members of the native majority.

Second, this means that we are able to separate bonding social capital within ethnic groups and bridging social capital between ethnic groups to test Putnam's core claims more rigorously. In contrast to studies focusing on either the majority perspective or the minority perspective, we combine both perspectives by using comparable measures of both in-group and out-group contacts and for both the ethnic majority and minority groups. This simultaneous assessment of the majority and minority is important for fully testing Putnam's argument that ethnic diversity decreases social contacts among both in-groups and out-groups.

Third, we examine effects of ethnic diversity at two levels, i.e. the municipality and the neighbourhood, which is quite exceptional in previous research (i.e. Letki, 2008). This enables us to examine at which contextual level ethnic diversity is most relevant. After all, since neighbourhoods are clustered in larger municipal contexts rather than being isolated, the municipality may influence social cohesion at the neighbourhood level over and beyond characteristics of the neighbourhood. In The Netherlands, neighbourhoods are less strongly segregated than in the United States. High ethnic diversity at the municipality level may increase personal contact with neighbours from other ethnic groups via personal contact with people in other social settings at the municipal level (e.g. work or school). Especially in the context of The Netherlands, it is therefore important to examine the possibility of effects of ethnic diversity at multiple hierarchical levels.

Fourth, in a similar way, whereas previous studies have indicated that other contextual characteristics (e.g. residential mobility or socio-economic deprivation) are more important than ethnic diversity in affecting social capital (e.g. Bécares et al., 2011; Gesthuizen et al., 2009; Laurence, 2011; Letki, 2008), the question whether these characteristics are especially important at the municipality level or at the neighbourhood level has remained unanswered. In this study, we examine at which contextual level these characteristics are most important for both the ethnic majority and minority groups, and for both intra-group and inter-group contact.

\section{Theory and hypotheses}

We use three competing theoretical approaches to derive hypotheses that provide preliminary answers to our research questions. First, we follow Putnam (2007), who argued that ethnic diversity would reduce bonding as well as bridging social capital. This would mean that the higher the level of ethnic diversity in a neighbourhood or municipality, the less personal contact people have with neighbours from their ethnic in-group as well as from other ethnic groups. According to this line of reasoning, also known as constrict theory (Gesthuizen et al., 2009; Savelkoul et al., 2011a), there is no reason to expect a difference in these relationships between the native majority and ethnic minorities. Put more concretely, building on Putnam's work, we perform a new rigorous test of the hunkering-down hypothesis:

Hypothesis 1: The higher the level of ethnic diversity in the neighbourhood/municipality: (a) the less ethnic majority members have informal contacts with in-group neighbours, (b) the less ethnic majority members have informal contacts with out-group neighbours, (c) the less ethnic minority members have informal contacts with in-group neighbours, (d) the less ethnic minority members have informal contacts with out-group neighbours.

Second, according to ethnic competition theory, ethnic diversity induces perceptions of threat among the native population by increasing competition over scarce material goods and cultural values (Savelkoul et al., 2011a, b; Schlueter and Scheepers, 2010; Schneider, 2008). These threat perceptions decrease trust in members of ethnic out-groups, which in turn reduces the native population's willingness to socially interact with ethnic minorities. As such, ethnic competition theory leads to the same prediction 
as constrict theory. However, contrary to constrict theory, ethnic competition theory does not suggest that high ethnic diversity also reduces contact with the ethnic in-group: ethnic diversity rather spurs in-group favouritism, meaning a stronger focus on social interaction with the ethnic in-group (Savelkoul et al., 2011a). These threat mechanisms may apply not only to the native population, but also to ethnic minority groups: high ethnic diversity may increase feelings of material and cultural threat imposed by the native majority as well as other ethnic minority groups. As a result, ethnic minority groups may also avoid contacts with the ethnic out-groups and invest mostly in contacts with the ethnic in-group in contexts with high ethnic diversity. In sum, the ethnic competition hypothesis suggests that ethnic diversity induces bonding social capital, yet reduces bridging social capital:

Hypothesis 2: The higher the level of ethnic diversity in the neighbourhood/municipality: (a) the more ethnic majority members have informal contacts with in-group neighbours, (b) the less ethnic majority members have informal contacts with out-group neighbours, (c) the more ethnic minority members have informal contacts with in-group neighbours, (d) the less ethnic minority members have informal contacts with out-group neighbours.

As a third theoretical perspective, we propose to build on insights from contact theory (Pettigrew and Tropp, 2006; Vervoort et al., 2010), according to which the higher the level of ethnic diversity in a neighbourhood or municipality the more personal contact they have with neighbours from other ethnic groups. This would apply equally to Dutch individuals and people of Turkish and Moroccan origin. We extend this line of reasoning by arguing that ethnic diversity may influence bonding and bridging social capital by inducing meeting opportunities with the native majority as well as the ethnic minorities. Through larger proportions of ethnic minority groups and smaller shares of ethnic majority members, high ethnic diversity at the neighbourhood and municipality level may simply increase opportunities for meeting ethnic minority groups, but also decrease opportunities for meeting the ethnic majority. Even though the homophily principle (Kalmijn, 1998; McPherson et al., 2001) states that people generally prefer to socialize with others who resemble themselves, there are fewer opportunities to do so if fewer people with similar traits are around. As a result, not only people of Turkish or Moroccan origin are expected to interact more with neighbours from ethnic minority groups as ethnic diversity is higher, but also native Dutch individuals. In more concrete terms, according to the meeting opportunities hypothesis, we would expect that:

Hypothesis 3: The higher the level of ethnic diversity in the neighbourhood/municipality: (a) the less ethnic majority members have informal contacts with in-group neighbours, (b) the more ethnic majority members have informal contacts with out-group neighbours, (c) the more ethnic minority members have informal contacts with in-group neighbours, (d) the less ethnic minority members have informal contacts with out-group neighbours from the ethnic majority, but the more they have informal contacts with out-group neighbours from other ethnic minorities.

\section{Data and measurements}

\section{Data}

To test our hypotheses we used data from the first wave of The Netherlands Longitudinal Lifecourse Study (NELLS; De Graaf et al., 2010). This survey was conducted between December 2008 and May 2010. Information was gathered partly through face-to-face interviews and partly through selfcompletion questionnaires. Respondents aged between 15 and 45 years of age were the target population. The data contain information on 5,312 individuals nested in 256 neighbourhoods (i.e. four-digit zip codes, which in The Netherlands include 4,080 inhabitants on average) from 35 municipalities in The Netherlands. The data include information on several characteristics at the neighbourhood and municipality level. A two-stage stratified sampling design was applied. First, a quasi-random selection of 35 
municipalities by region and urbanization was made and, second, a random selection from the population registry based on age and country of birth of the respondent and his/her parents (De Graaf et al., 2010). Importantly, two of the largest immigrant groups in The Netherlands (i.e. Moroccans and Turks) were oversampled in the NELLS data. As a result, a unique advantage of this data set over other data sources is that it allows for a comparison between native Dutch individuals and immigrants rather than a focus exclusively on one of these two groups. The survey yielded an overall response of 52 per cent, which is about equal to similar surveys in The Netherlands. The data are largely representative of the general Dutch population aged between 15 and 45 . However, women, older respondents and respondents living in moderately urbanized municipalities are overrepresented (De Graaf et al., 2010).

We combined information on the respondents' country of birth and the parental countries of birth to determine ethnicity. Respondents are considered to be Dutch if both parents were born in The Netherlands. If the mother was born outside The Netherlands, the mother's country of origin was used to assign respondents to ethnic groups. In the event the mother was born in The Netherlands and the father outside The Netherlands, the father's country of birth was used to indicate ethnic group membership.

In this study, we limited ourselves to a comparison of people of Turkish and Moroccan descent and native Dutch respondents. Hence, information on 455 individuals from other ethnic groups was not used, leaving an initial sample of 4,857 respondents: 2,556 native Dutch respondents, ${ }^{1} 1,137$ respondents of Turkish origin and 1,166 of Moroccan origin. After listwise deletion of missing information on all variables, 4,366 respondents remain available for analysis, i.e. 10.1 per cent of the initial sample is lost because of missing data. This is mostly due to missing information on the dependent variables: depending on the outcome variable that is used, a total of around 400 respondents could not be included in the analyses for this reason.

\section{Measurements}

To measure informal personal contact with neighbours both within and across the boundaries of their own ethnic group, respondents were asked how often they had personal contact with people from four ethnic groups (i.e. Dutch origin, Turkish origin, Moroccan origin, Surinamese/Antillean origin) in their neighbourhood. $^{2}$ Hence, for the three main ethnic groups in our study we are able to examine personal contact with neighbours from the ethnic in-group and the two ethnic out-groups, plus personal contact with a group that is an ethnic out-group for all respondents in our sample. For each ethnic group, respondents were asked a separate question, offering seven answer categories: (1) (almost) daily, (2) once or several times per week, (3) several times per month, (4) about once per month, (5) several times per year, (6) about once per year, and (7) never. Importantly, in putting this question to the respondents the interviewer emphasized that 'personal contact' was defined as knowing the other person's name and talking to this person occasionally. Hence, encounters between neighbours without any further communication are not covered by this measure, thereby strengthening its validity as a measure of informal social capital. The four dependent variables were recoded such that a high score represents a high frequency of personal contact.

To measure ethnic diversity at the neighbourhood and municipality level, we obtained information on the total proportion of non-Western immigrants from Statistics Netherlands (2011). ${ }^{3}$ At both the neighbourhood and municipality levels, three control variables were taken into account, all derived from Statistics Netherlands (2011). The number of departures per 1,000 inhabitants (measured in 2004) was included to account for residential mobility, and divided by 10 to facilitate the interpretation of coefficients. To control for the socio-economic situation at the neighbourhood and municipality levels, we included the average income per person after tax (including wages and transfers, measured in 2007) and the number of unemployment benefit recipients per 1,000 inhabitants aged 15-64 (divided by 10, measured in 2006).

At the individual level, ethnicity was included in the analyses by taking native Dutch respondents as the reference group, and assigning separate dummy variables to respondents of Turkish and Moroccan origin. We controlled for nine variables to account for compositional differences between neighbourhoods and 
municipalities. Gender was controlled for by coding men as 0 and women as 1 . Respondents' age was included in years, and we subtracted the minimum age observed (i.e. 14 years) such that a score of 0 represents the age of 14 years old. We accounted for the educational level by including the highest obtained level of education for those respondents who indicated that they had completed their educational career. For respondents who were still in school or studying at the moment of the interview, we included the level of education of the track they were following at that time. We coded the educational level as a continuous variable with 11 categories ranging from 'No education/did not complete elementary school' $(0)$ to ' $\mathrm{PhD}$ ' (11). To measure religiosity, respondents were asked whether they had prayed in the last three months $(0=$ no, $1=$ yes). The advantage of this measure of religious involvement over measures such as denominational membership or religious attendance is that prayer is most comparable across ethnic groups and cultures as an indicator of religiosity. We included a measure of verbal ability to account for language proficiency (after all, limited mastery of the Dutch language limits the possibility to interact with Dutch neighbours, as well as with neighbours from other ethnic minority groups). To measure verbal ability, both native and non-native respondents were confronted with nine Dutch words and asked to specify the meaning of the word. For each word, four answer categories were offered, with only one being correct (additionally, respondents had the possibility to select the 'don't know' category). The verbal ability score was then computed by summing the number of right answers, resulting in a variable ranging from 0 (none answered correctly) to 9 (all answered correctly). We included dummy variables indicating whether people were currently at school or studying $(0=$ no, $1=$ yes $)$ or in paid employment $(0=$ no, $1=$ yes $)$. Additionally, we controlled for having a partner $(0=$ no, $1=$ yes $)$ and having children $(0=$ no, $1=$ yes $)$. Descriptive statistics of all variables at the individual, neighbourhood and municipality levels are presented in Table 1.

\section{Statistical analyses}

We performed multi-level linear regression analyses to deal with the nested structure of the data. Each of the four dependent variables was analysed separately. Three-level models were performed, with municipalities as the highest hierarchical level, neighbourhoods as the middle level and individuals as the lowest. Failing to account for the fact that individuals are hierarchically nested in neighbourhoods and municipalities would result in underestimation of standard errors of effects of neighbourhood and municipality characteristics (Snijders and Bosker, 1999). A standard estimation procedure was used, where no restrictions were imposed on the models, none of the variables was centred, and effects of individual variables were not allowed to vary randomly across neighbourhoods or municipalities. In all models, we show unstandardized regression coefficients $(B)$, standard errors (S.E.) and variance components at the individual, neighbourhood and municipality levels. Additionally, we report -2 Log Likelihood estimates, with lower values indicating better model fit. For all four dependent variables, we first present empty variance component models. This enables us to examine the extent to which variation in the dependent variables is located at the individual, neighbourhood and municipality levels. Second, we estimated models in which the individual level variables were added to the equation, without yet including the neighbourhood and municipality level variables. As a third step, we added all neighbourhood and municipality level indicators to the analyses. Sensitivity analyses (available upon request) including the neighbourhood level variables on the one hand and the municipality level variables on the other separately did not lead to substantively different conclusions. Hence, we do not present and discuss the results of these separate-level models in this study. Fourth, as our final and most important step, we included interaction terms between individual ethnicity and ethnic diversity at the neighbourhood and municipality level to examine whether effects of ethnic diversity on contacts with neighbours are different between ethnic groups. We performed perturbation analyses (Van der Meer et al., 2010) to check the robustness of our findings. This was done by adding small random errors to the measures at the neighbourhood and municipality levels, and then re-estimating the models 100 times using different random errors in each estimation. The results of this procedure (available upon request) revealed that 
Table I. Descriptive statistics of the individual, neighbourhood and municipality level characteristics.

\begin{tabular}{|c|c|c|c|c|}
\hline & $N$ & Range & Mean & SD \\
\hline \multicolumn{5}{|l|}{ Dependent variables } \\
\hline Frequency of personal contact with Dutch neighbours & 4358 & $0-6$ & 4.785 & 1.590 \\
\hline Frequency of personal contact with Turkish neighbours & 4353 & $0-6$ & 2.356 & 2.410 \\
\hline Frequency of personal contact with Moroccan neighbours & 4353 & $0-6$ & 2.234 & 2.414 \\
\hline Frequency of personal contact with Surinamese/Antillean neighbours & 4347 & $0-6$ & $\mathrm{I} .545$ & 2.080 \\
\hline \multicolumn{5}{|l|}{ Individual characteristics } \\
\hline \multicolumn{5}{|l|}{ Ethnicity } \\
\hline Dutch & 4366 & $0 / 1$ & 0.551 & \\
\hline Turkish & 4366 & $0 / 1$ & 0.224 & \\
\hline Moroccan & 4366 & $0 / 1$ & 0.226 & \\
\hline Age $(14=0)$ & 4366 & $0-35$ & 17.386 & 9.026 \\
\hline Gender (female $=1$ ) & 4366 & $0 / 1$ & 0.532 & \\
\hline Educational level & 4366 & $0-11$ & 5.516 & 2.940 \\
\hline Prayed in last three months & 4366 & $0 / 1$ & 0.527 & \\
\hline Currently at school & 4366 & $0 / 1$ & 0.251 & \\
\hline In paid employment & 4366 & $0 / 1$ & 0.755 & \\
\hline Partner & 4366 & $0 / 1$ & 0.692 & \\
\hline Children & 4366 & $0 / 1$ & 0.523 & \\
\hline Verbal ability & 4366 & $0-9$ & 4.976 & 2.777 \\
\hline \multicolumn{5}{|l|}{ Neighbourhood characteristics } \\
\hline Proportion of non-Western ethnic minorities & 256 & $0.01-0.85$ & 0.173 & 0.165 \\
\hline Departures per I,000 inhabitants $(/ 10)$ & 256 & $3.90-29.90$ & 11.247 & 4.049 \\
\hline Average income per person & 256 & $8.20-24.40$ & 12.686 & 1.472 \\
\hline Unemployed per 1,000 inhabitants $(/ 10)$ & 256 & $0.00-6.70$ & 3.303 & 1.155 \\
\hline \multicolumn{5}{|l|}{ Municipality characteristics } \\
\hline Proportion of non-Western ethnic minorities & 35 & $0.01-0.36$ & 0.144 & 0.106 \\
\hline Departures per I,000 inhabitants $(/ I 0)$ & 35 & $5.84-17.05$ & 11.076 & 3.135 \\
\hline Average income per person & 35 & $12.70-16.40$ & 14.089 & 0.863 \\
\hline Unemployed per 1,000 inhabitants $(/ / 0)$ & 35 & $1.00-5.20$ & 3.237 & 0.779 \\
\hline
\end{tabular}

Source: Netherlands Longitudinal Lifecourse Study (NELLS, 2010).

the introduction of random errors leads to substantively similar conclusions. We therefore conclude that our results are robust to instability of our neighbourhood and municipality characteristics due to limited sample size at these levels.

\section{Results}

Before turning to the results of the multi-level regression analyses, we examine the extent to which the three ethnic groups in our study differ with regard to their frequency of contact with neighbours in their ethnic ingroup and out-groups. Table 2 presents the distribution of the four dependent variables separately for the three ethnic groups in our study. For all of them we find that over 70 per cent of respondents have personal contact with Dutch neighbours at least once a week. Interestingly, respondents of Turkish and Moroccan origin have hardly any less personal contact with Dutch neighbours than native Dutch respondents. Additionally, Table 2 demonstrates that people from Turkish and Moroccan origin have about the same frequency of personal contact with neighbours from their own ethnic group as native Dutch respondents. However, the majority of Dutch respondents never have personal contact with neighbours of Turkish, Moroccan or Surinamese/Antillean origin. Finally, there appears to be more inter-group contact between Turkish and 
Table 2. Distribution of frequency of personal contact with neighbours from four ethnic groups of origin. Presented separately for native Dutch respondents, people from Turkish origin and people from Moroccan origin.

\begin{tabular}{|c|c|c|c|c|c|c|c|c|c|c|c|c|}
\hline & \multicolumn{3}{|c|}{$\begin{array}{l}\text { Contact with } \\
\text { native Dutch } \\
\text { neighbours }\end{array}$} & \multicolumn{3}{|c|}{$\begin{array}{l}\text { Contact with } \\
\text { neighbours of } \\
\text { Turkish origin }\end{array}$} & \multicolumn{3}{|c|}{$\begin{array}{l}\text { Contact with } \\
\text { neighbours of } \\
\text { Moroccan origin }\end{array}$} & \multicolumn{3}{|c|}{$\begin{array}{l}\text { Contact with neigh- } \\
\text { bours of Surinamese/ } \\
\text { Antillean origin }\end{array}$} \\
\hline & NL & TU & MO & NL & TU & MO & NL & TU & MO & NL & TU & MO \\
\hline ever & 4.0 & 6.9 & 7. & 64.2 & 9.2 & 31.4 & 67.9 & 34.7 & 10.8 & 68.8 & 46.7 & 43.4 \\
\hline About once per year & 0.8 & 0.9 & I.I & 5.1 & 0.7 & 4.0 & 4.6 & 3.8 & $\mathrm{I} .4$ & 4.3 & 4.9 & 3.8 \\
\hline Several times per year & 3.4 & 4.3 & 2.7 & 7.2 & 3.5 & 6.5 & 7.5 & 8.4 & 2.6 & 6.9 & 9.0 & 6.3 \\
\hline About once per month & 4.5 & 4.9 & 5. & 6.4 & 5.3 & 7.9 & 5.3 & 7.0 & 4.0 & 5.1 & 6.8 & 6.5 \\
\hline $\begin{array}{l}\text { Several times per } \\
\text { month }\end{array}$ & 14.4 & 12.1 & 11.9 & 7.5 & 8.3 & 12.8 & 6.7 & 13.8 & 9.5 & 7.3 & 11.8 & 11.5 \\
\hline $\begin{array}{l}\text { Once or several times } \\
\text { per week }\end{array}$ & 26.0 & 32.9 & 34.1 & 6.7 & 29.7 & 24.4 & 5.1 & 20.4 & 26.2 & 5.0 & 14.7 & 18.2 \\
\hline (Almost) daily & 47.0 & 38.1 & 37.1 & 3.0 & 43.2 & 13.0 & 2.9 & 11.8 & 45.6 & 2.5 & 6.1 & 10.2 \\
\hline Total $(N)$ & 2466 & 1001 & 1002 & 2462 & 999 & 1000 & 2461 & 997 & 1004 & 2463 & 994 & 999 \\
\hline Missing & 90 & 136 & 162 & 94 & 138 & 164 & 95 & 140 & 160 & 93 & 143 & 165 \\
\hline
\end{tabular}

Source: Netherlands Longitudinal Lifecourse Study (NELLS, 2010).

$\mathrm{NL}=$ native Dutch, $\mathrm{TU}=$ Turkish origin, $\mathrm{MO}=$ Moroccan origin.

Moroccan neighbours than between Dutch neighbours and either of these two groups. Similarly, people from Turkish origin and respondents from Moroccan origin have more personal contact with people from Surinamese/Antillean origin than Dutch respondents. Finally, Table 2 reveals that for all four dependent variables about 10 per cent of the respondents of Turkish and Moroccan origin are lost due to missing information, whereas this is only about 4 per cent for native Dutch respondents. In sum, although there appears to be frequent inter-ethnic contact in The Netherlands, Table 2 suggests that only a small minority of native Dutch neighbours accounts for most personal contact with ethnic minority groups.

In Table 3, we present results of multi-level linear models regressing frequency of contact with neighbours from four ethnic groups on individual ethnicity and control variables. In Model A, we estimated the variance components for all four dependent variables without including any independent variables. ${ }^{4}$ Model A reveals that the municipality and neighbourhood levels can hardly account for differences between respondents in their frequency of personal contact with Dutch neighbours. On the other hand, differences between respondents in the frequency of contact with Turkish and Moroccan neighbours appear to be largely determined by factors at the neighbourhood and municipality levels. Hence, just examining personal contact with the ethnic majority group without including personal contact with ethnic minorities would lead to completely different conclusions on the potential impact of the municipal and neighbourhood context on informal social capital.

In Model B, all characteristics at the individual level were added to the analysis. Controlling for the other individual characteristics, there is no significant difference between the three ethnic groups in the frequency of personal contact with Dutch neighbours. Yet, respondents from Turkish and Moroccan origin have more frequent personal contact with Turkish neighbours than the Dutch natives. The same applies to personal contact with Moroccan neighbours and, to a lesser extent, with Surinamese/Antillean neighbours. Not surprisingly, ethnic minorities report most personal contact with neighbours of their ethnic in-group, which corresponds to the homophily principle (McPherson et al., 2001) and the findings presented in Table 2. However, for frequency of personal contact with the native majority, ethnicity does not appear to be important. ${ }^{5}$

In Table 4, characteristics at the neighbourhood and municipality levels were added to the equation. Note that we controlled for the same individual level characteristics as in Table 3. However, since the effects of these characteristics hardly changed after including neighbourhood and municipality variables, 


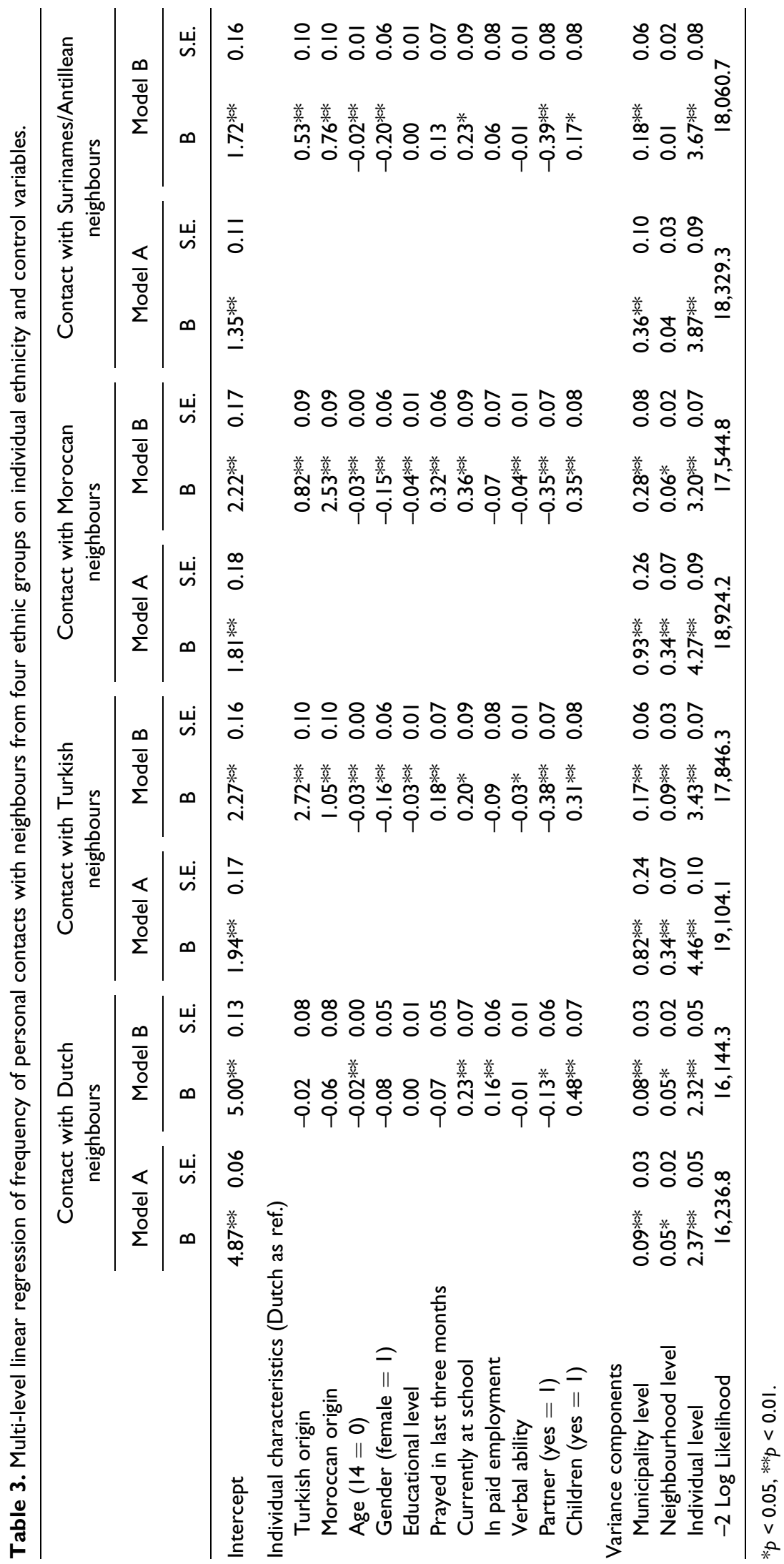


we did not present effects of the individual control variables in Table 4. In Model C, we present results of analyses in which the effects of neighbourhood and municipality characteristics on the four dependent variables were estimated without the inclusion of interaction terms between ethnic diversity and ethnicity. Finally, in Model D we added interaction terms between individual ethnicity and neighbourhood and municipality level ethnic diversity to the analysis to examine whether the effects of ethnic diversity on personal contact with neighbours are different across ethnic groups. Note that the results presented in Model D are most important for the evaluation of our hypotheses, because these reveal the extent to which ethnic diversity has differential effects on in-group and out-group contact, for both the ethnic majority and ethnic minority groups.

First, we examine personal contact with Dutch neighbours. In Model C, the proportion of nonWestern ethnic minorities at the neighbourhood level as well as the municipality level is negatively related to the frequency of personal contact with Dutch neighbours. Hence, in concordance with Putnam (2007), high ethnic diversity appears to reduce personal contact with the native majority. Model D shows that the associations between neighbourhood and municipality level ethnic diversity, on the one hand, and personal contact with Dutch neighbours, on the other, do not differ significantly across ethnic groups. This model also reveals that the effect of ethnic diversity is not significant for the reference group (i.e. native Dutch respondents), although the effect of ethnic diversity at the municipality level is close to significance. Based on these results, the hunkering-down hypothesis, the ethnic competition hypothesis and the meeting opportunities hypothesis are all largely rejected, since ethnic diversity is not significantly related to either personal contacts within the Dutch in-group or to contacts of Turks and Moroccans with their ethnic out-group.

Second, we focus on personal contact with Turkish and Moroccan neighbours: results are largely similar for these two outcome variables. According to Model C, a high proportion of non-Western ethnic minorities at the neighbourhood level appears to increase personal contact with Turkish and Moroccan neighbours, whereas ethnic diversity at the municipality level does not appear to be relevant. Model D shows that for personal contact with Turkish neighbours these associations do not differ between native Dutch, Turkish and Moroccan respondents. These results are in line with the meeting opportunities hypothesis. For respondents of Moroccan origin, the positive association between the proportion of non-Western ethnic minorities at the neighbourhood level and personal contact with Moroccan neighbours is significantly weaker than for native Dutch respondents. People of Moroccan origin interact with neighbours from their ethnic in-group regardless of the ethnic composition of their neighbourhood. All in all, the hunkering-down hypothesis and the ethnic competition hypothesis are rejected here: ethnic diversity does not affect personal contact negatively for any group and is only associated with more in-group contacts for Turkish respondents, but not for Moroccans.

Finally, we discuss the results for personal contact with Surinamese/Antillean neighbours. Model C reveals that respondents report more personal contact with Surinamese/Antillean neighbours as the proportion of non-Western ethnic minorities at the municipality level is higher. However, contact with Surinamese/Antillean neighbours is not influenced by ethnic diversity at the neighbourhood level. Looking at Model D, the effect of the proportion of non-Western ethnic minorities at the neighbourhood level on personal contact with Surinamese/Antillean neighbours is significantly weaker for respondents of Moroccan origin compared with native Dutch respondents. However, for both groups, ethnic diversity at the neighbourhood level is not significantly related to personal contact with Surinamese/Antillean neighbours (the main effect of the proportion of non-Western minorities is not significant). On the other hand, the effect of the proportion of non-Western ethnic minorities at the municipality level on personal contact with Surinamese/Antillean neighbours is significantly stronger for respondents of Moroccan origin. In sum, whereas ethnic diversity is not significantly related to personal contact with Surinamese/Antillean neighbours among Dutch and Turkish respondents, it appears to increase personal contact with Surinamese/Antillean neighbours among people of Moroccan origin. This means that the hunkering-down hypothesis and the ethnic competition hypothesis are rejected by these results, whereas the meeting opportunities hypothesis receives partial support. 6,7 


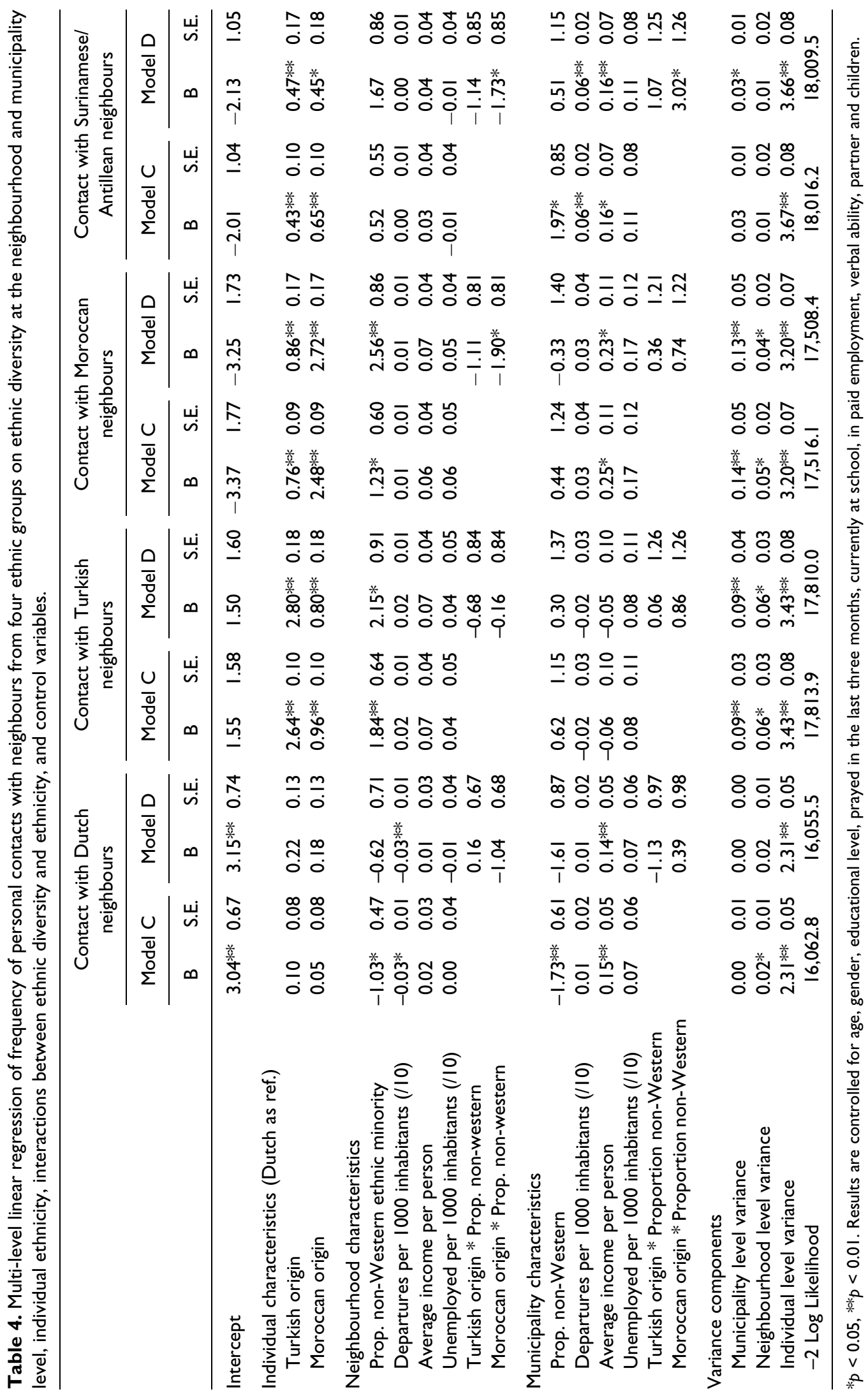


Table 5. Schematic overview of support and rejection of hypotheses.

Contact with

\begin{tabular}{cccc}
\hline Dutch & Turkish & Moroccan & $\begin{array}{c}\text { Surinamese/ } \\
\text { Antillean }\end{array}$ \\
neighbours & neighbours & neighbours & neighbours \\
\hline
\end{tabular}

Hunkering down hypothesis $(\mathrm{HI})$ : The higher the level of ethnic diversity in the neighbourhood/municipality:

(a) the less ethnic majority members have informal contacts with in-group neighbours

(b) the less ethnic majority members have informal contacts with out-group neighbours

(c) the less ethnic minority members have informal contacts with in-group neighbours

(d) the less ethnic minority members have informal contacts with out-group neighbours

Ethnic competition hypothesis $(\mathrm{H} 2)$ : The higher the level of ethnic diversity in the neighbourhood/municipality:

(a) the more ethnic majority members have informal contacts with in-group neighbours

(b) the less ethnic majority members have informal contacts with out-group neighbours

(c) the more ethnic minority members have informal contacts with in-group neighbours

(d) the less ethnic minority members have informal contacts with out-group neighbours

Meeting opportunities hypothesis $(\mathrm{H} 3)$ : The higher the level of ethnic diversity in the neighbourhood/municipality:

(a) the less ethnic majority members have informal contacts with in-group neighbours

(b) the more ethnic majority members have informal contacts with out-group neighbours

(c) the more ethnic minority members have informal contacts with in-group neighbours

(d) the less ethnic minority members have informal contacts with out-group neighbours from the ethnic majority, but the more they have informal contacts with out-group neighbours from other ethnic minorities

$\begin{array}{cccc}(+) & \text { n.a. } & \text { n.a. } & \text { n.a. } \\ \text { n.a. } & - & - & - \\ \text { n.a. } & - & - & \text { n.a. } \\ - & - & - & -\end{array}$

$\begin{array}{cccc}- & \text { n.a. } & \text { n.a. } & \text { n.a. } \\ \text { n.a. } & - & - & - \\ \text { n.a. } & + & - & \text { n.a. } \\ - & - & - & -\end{array}$

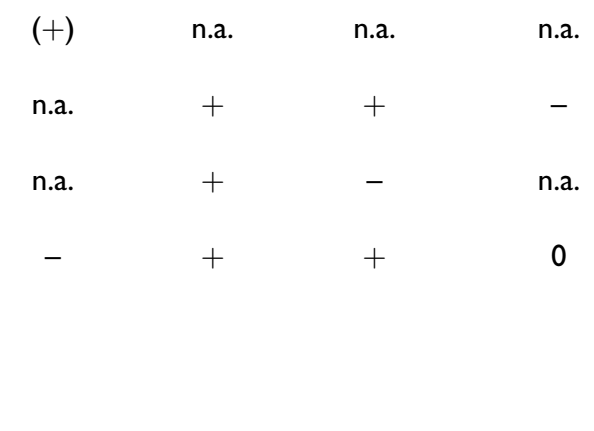

$+=$ hypothesis supported; $(+)=$ hypothesis supported in main effects model, but rejected in group-specific interaction model; $-=$ hypothesis rejected; $0=$ mixed evidence; n.a. $=$ not applicable.

Since discussing all tests of the hypotheses in detail would be too elaborate (i.e. a total of 30 tests of hypotheses were performed in this article), we summarize all tests of our specific hypotheses in Table 5, in which a schematic overview of the evaluation of all specific hypotheses is reported. All expectations that followed from the hunkering-down hypothesis are rejected by our group-specific interaction models, although the main effects models support this hypothesis for contacts with Dutch neighbours. The ethnic competition hypothesis is largely rejected as well, since only one out of ten specific hypotheses is supported. The meeting opportunities hypothesis is largely supported and clearly outperforms the other hypotheses. 


\section{Conclusion and discussion}

In this study, we aimed to put Putnam's (2007) claim to a new test that ethnic diversity decreases bonding as well as bridging social connections. We added to earlier research by examining informal social capital of people from the ethnic in-group as well as the ethnic out-groups in The Netherlands. By including both native Dutch individuals and people from Turkish and Moroccan origin and using comparable measures, we were able to combine a majority perspective and a minority perspective to perform tests on bonding as well as bridging social capital. We used personal contact with neighbours as a measure of informal social capital, and estimated the effect of ethnic diversity, next to other rival determinants, at both neighbourhood and municipality levels. Hence, we answered two main research questions in this study: (1) the extent to which living in neighbourhoods and municipalities in The Netherlands with different levels of ethnic diversity is negatively related to informal personal contact with neighbours from both the ethnic in-group and ethnic out-groups, and (2) the extent to which these relationships differ between the native Dutch majority and ethnic minorities.

Three theoretical perspectives were contrasted to provide answers to these questions. First, according to constrict theory (Putnam, 2007), in neighbourhoods and municipalities with high levels of ethnic diversity, people would have less personal contact with neighbours from their own ethnic group as well as neighbours from other ethnic groups. This would apply to both the native majority and to people of Turkish and Moroccan origin. Our results show that ethnic diversity increases personal contact with neighbours of Turkish, Moroccan and Surinamese or Antillean origin, while negatively affecting personal contact with native Dutch neighbours. There are hardly any differences in these relationships between the native Dutch majority and ethnic minority groups. Hence, despite the negative association between ethnic diversity and contact with Dutch natives, constrict theory gains little support in this study.

Second, according to ethnic competition theory (Savelkoul et al., 2011a, b; Schlueter and Scheepers, 2010; Schneider, 2008), high ethnic diversity would be associated with less personal contact with neighbours from ethnic out-groups, but more personal contact with neighbours from the ethnic ingroup. Again, this would apply to members of both the native majority and members from the Turkish and Moroccan minority groups. We found that native Dutch individuals have more rather than less personal contact with neighbours from ethnic minority groups if they live in neighbourhoods with higher levels of ethnic diversity. This means that ethnic competition theory is contradicted by our findings: high ethnic diversity is not associated with less contact with ethnic out-groups and more contact with the ethnic ingroup among native majority members. The presence of ethnic minorities in neighbourhoods and municipalities that parallels ethnic diversity does not appear to reduce social interaction between ethnic groups.

Third, we extended contact theory (Pettigrew and Tropp, 2006) by deriving the meeting opportunities hypothesis: higher levels of ethnic diversity would not only increase the opportunities for personal contact with neighbours from ethnic minority groups, but also decrease personal contact with neighbours from the Dutch majority. This mechanism should apply equally for the native majority and ethnic minority groups. Our results point towards partial support for this theoretical perspective: neighbourhoods and municipalities with high ethnic diversity offer fewer opportunities for interacting socially with native Dutch individuals. However, this association is not found when the three ethnic groups are analysed separately. On the other hand, ethnically diverse neighbourhoods have more opportunities for meeting people of Turkish and Moroccan origin. Instead of inducing people to hunker down, ethnic diversity actually seems to change the ethnicity of the neighbours people interact with.

There are a number of findings that deserve further attention in future research. First, while personal contact with Turkish and Moroccan neighbours appears to be influenced by ethnic diversity only at the neighbourhood level, personal contact with Dutch and Surinamese or Antillean neighbours is mostly affected by ethnic diversity at the municipality level. Additionally, there appears to be stronger variation in personal contact with neighbours between municipalities than between neighbourhoods. This underlines the relevance of distinguishing multiple contextual levels instead of solely focusing on neighbourhoods. Second, in contrast to several other studies in this field (e.g. Laurence, 2011; Letki, 2008), 
we found hardly any effects of socio-economic characteristics at the municipality and particularly the neighbourhood level. Socio-economic affluence as measured by the average income was influential only at the municipality level, whereas disadvantage as measured by the level of unemployment did not affect personal contact with neighbours at all. Future research should further specify under which conditions socio-economic affluence and disadvantage influence social capital.

Finally, there are some limitations to this study. First, we used the proportion of non-Western ethnic minorities as an indicator of ethnic diversity. As mentioned, correlations between this indicator and other measures of ethnic diversity, such as the Herfindahl index, were extremely high. Nevertheless, it would be preferable to disentangle the effects of the proportion of ethnic minorities and the degree of ethnic heterogeneity on social capital. However, this would require data in which the proportion of ethnic minorities and the degree of ethnic heterogeneity are correlated only modestly at the neighbourhood or municipality level. Therefore, it remains to be questioned whether it is heterogeneity as such or the presence of ethnic minorities from whichever ethnic group that most strongly determines bonding and bridging social connections.

Second, although the NELLS data offered some unique advantages for this study's objectives, there were limitations as well. First, only respondents aged 15 to 45 were included in the data, which means that we cannot generalize our findings to older age groups. Especially for older native Dutch respondents, it would have been interesting to examine whether high ethnic diversity also leads to less personal contact with Dutch neighbours and more personal contact with neighbours from ethnic minorities. After all, their opportunities to meet non-native neighbours through settings such as school and work may be fewer than for the younger age groups. Additionally, it would have been interesting to examine respondents of Surinamese and Antillean origin, because then we could have investigated the extent to which individuals from this group have personal contact with neighbours from their own ethnic in-group. Unfortunately, the NELLS data did not include enough individuals from these ethnic groups to allow for such an investigation. Finally, because the NELLS data are cross-sectional, we were not able to separate causal effects and selection effects or to rule out unobserved heterogeneity in our results.

All in all, this study calls into question Putnam's (2007) claim that ethnic diversity erodes social capital. Rather, ethnic diversity provides opportunities to meet people from ethnic minority groups, yet limits the opportunities to interact with the ethnic majority. Although ethnic diversity therefore appears to be beneficial for the native majority becoming acquainted with ethnic minorities, ethnic diversity does put constraints on the possibilities of ethnic minorities getting in touch with neighbours from the native majority. This would mean that, even without support for the hunkering-down hypothesis, ethnic diversity may to some extent hamper social integration of ethnic minorities in the host society. The fact that the hunkering-down hypothesis is contradicted in the Dutch context, where informal social capital is abundantly present, underlines the question marks to be placed with Putnam's claims. Future research, preferably examining multiple societies simultaneously with comparable data, should investigate whether combining the majority and minority perspective in analysing other indicators of social capital, such as trust or involvement in voluntary organizations, would lead to similar conclusions.

\section{Funding}

This research was part of a project entitled 'Relationships of ethnic diversity in local communities with solidarity regarding the in-group and exclusion of out-groups' (project number 432-008-005), which was funded by the Dutch Organization for Scientific Research.

\section{Notes}

1. The group of native Dutch respondents does not include Western immigrants. These were not included in our sample.

2. The data also contained a similar item on the frequency of personal contact with other non-Western ethnic groups. We decided not to use it because of the heterogeneous composition of the other non-Western ethnic groups in The Netherlands. 
3. Instead of using the proportion of ethnic minorities as a measure of ethnic diversity, previous research has often used a Herfindahl index to indicate the level of ethnic heterogeneity (e.g. Putnam, 2007). However, since the correlation between the proportion of non-Western ethnic minorities and the Herfindahl index is extremely high at both the neighbourhood and municipality levels (Pearson's $r>0.95$ ) we were unable to include both measures simultaneously in our models. Nevertheless, to examine whether using other measures of ethnic diversity would lead to different conclusions, we did several sensitivity analyses (i.e. using the total proportion of Western and nonWestern ethnic minorities, and using a Herfindahl index distinguishing native Dutch people, people of Moroccan origin, Turkish origin, Western origin and non-Western origin at the neighbourhood and municipality levels). The results (available upon request) indicate that using different measures of ethnic diversity leads to substantially similar conclusions. Since our results based on the proportion of non-Western ethnic groups are slightly more robust, and since the Herfindahl index is colour blind (i.e. the index does not acknowledge that high diversity due to 20 per cent ethnic minority members and 80 per cent majority members may have different effects from high diversity because of 80 per cent ethnic minority members and 20 per cent majority members) we decided to present this measure of ethnic diversity in our main models.

4. For personal contact with Dutch neighbours, the variance components at the municipality, neighbourhood and individual levels amount to $0.09,0.05$ and 2.37 , respectively. This means that 94.4 per cent of the variation in contact with Dutch neighbours $(=(2.37 /(0.09+0.05+2.37)) * 100)$ is located at the individual level. The municipality level accounts for 3.6 per cent of the variation in personal contact with Dutch neighbours, whereas a mere 1.9 per cent of the variation in personal contact with Dutch neighbours is located at the neighbourhood level. Using similar calculations, Model A shows that 79.3 per cent of the variation in personal contact with Turkish neighbours is located at the individual level, whereas the municipality level (14.6 per cent) and the neighbourhood level ( 6.0 per cent) account for a smaller share of the variation. For the variation in personal contact with Moroccan neighbours, these shares amount to 77. 1 per cent (individual level), 16.8 per cent (municipality level) and 6.1 per cent (neighbourhood level). Finally, variation in personal contact with Surinamese/Antillean neighbours is mostly located at the individual level (90.6 per cent), followed by the municipality level (8.4 per cent). There is no significant variation in personal contact with Surinamese/Antillean neighbours between neighbourhoods.

5. Effects of the individual level control variables on personal contact with neighbours are in line with findings from earlier research. For personal contact with Dutch neighbours, the variance components hardly decrease after including the individual characteristics. For personal contact with Turkish and Moroccan neighbours, however, all variance components, but especially municipality and neighbourhood level variance, decrease dramatically after controlling for individual characteristics. For personal contact with Surinamese/Antillean neighbours, the decrease is less strong, but still substantial at the municipality level. Whereas differences between respondents in the frequency of personal contact with Dutch neighbours can hardly be explained by the individual characteristics in our model, these characteristics are to a substantial amount able to account for variation in personal contact with Turkish and Moroccan neighbours.

6. The control variables at the neighbourhood and municipality levels appear to influence personal contact with neighbours only to a limited extent. High residential mobility (as measured by departures per 1,000 inhabitants) at the neighbourhood level is associated with less personal contact with Dutch neighbours, but does not affect personal contact with neighbours from other ethnic groups. On the other hand, high residential mobility at the municipality level does not affect personal contact with neighbours, except for personal contact with Surinamese/Antillean neighbours, which is more frequent in municipalities with high residential mobility. Possibly, people of Surinamese/Antillean origin mostly live in municipalities 
with the highest levels of residential mobility, which could explain this counterintuitive finding. The average income at the neighbourhood level is not significantly related to personal contact with neighbours from any ethnic group. At the municipality level, however, there is more personal contact with Dutch, Moroccan and Surinamese/Antillean neighbours as the average income is higher (contact with people from Turkish origin is not influenced by the average municipal income). Hence, our results partly corroborate earlier work in this field, in which it was argued that affluence and socio-economic advantage is an important determinant of social capital (Letki, 2008; Tolsma et al., 2009). However, the level of unemployment does not significantly influence personal contact with neighbours from any ethnic group, either at the neighbourhood or at the municipality level. This contradicts earlier findings on the importance of socio-economic disadvantage for informal social contact (Letki, 2008).

7. The variance components reveal that municipality level variance in particular is decreased quite strongly after inclusion of the characteristics at the neighbourhood and municipality levels. For personal contact with Dutch and Surinamese/Antillean neighbours, variation between municipalities even turns nonsignificant in Model C, which means that the characteristics in our model explain why municipalities differ in their frequency of personal contact with Dutch and Surinamese/Antillean neighbours.

\section{References}

Bécares L, Stafford M, Laurence J and Nazroo J (2011) Composition, concentration and deprivation: Exploring their association with social cohesion among different ethnic groups in the UK. Urban Studies. Epub ahead of print 1 June 2012. doi: 10.1077/0042098010391295.

Castles S and Miller MJ (2003) The Age of Migration: International Population Movements in the Modern World. New York: Guildford Press.

De Graaf PM, Kalmijn M, Kraaykamp G and Monden C (2010) The Netherlands Longitudinal Lifecourse Study (NELLS Wave 1). Dataset. Tilburg University \& Radboud University Nijmegen, Netherlands.

Gesthuizen M, Van der Meer T and Scheepers P (2009) Ethnic diversity and social capital in Europe: Tests of Putnam's thesis in European countries. Scandinavian Political Studies 32(2): 121-142.

Gijsberts M, Huijnk W and Dagevos J (2012) Jaarrapport integratie 2011. Den Haag: Sociaal en Cultureel Planbureau.

Gijsberts M, Van der Meer T and Dagevos J (2011) 'Hunkering down' in multi-ethnic neighbourhoods? The effects of ethnic diversity on dimensions of social cohesion. European Sociological Review. Epub ahead of print 1 June 2012. doi: 10.1093/esr/jcr022.

Hooghe M, Reeskens T, Stolle D and Trappers A (2009) Ethnic diversity and generalized trust in Europe. A cross-national multilevel study. Comparative Political Studies 42(2): 198-223.

Kalmijn M (1998) Intermarriage and homogamy: Causes, patterns, trends. Annual Review of Sociology 24: $395-421$.

Laurence J (2011) The effect of ethnic diversity and community disadvantage on social cohesion: A multi-level analysis of social capital and interethnic relations in UK communities. European Sociological Review 27(1): 70-89.

Letki N (2008) Does diversity erode social cohesion? Social capital and race in British neighborhoods. Political Studies 56(1): 99-216.

McPherson M, Smith-Lovin L and Cook JM (2001) Birds of a feather: Homophily in social networks. Annual Review of Sociology 27: 415-444.

Pettigrew TF and Tropp LR (2006) A meta-analytic test of intergroup contact theory. Journal of Personality and Social Psychology 90(5): 751-783.

Pichler F and Wallace C (2007) Patterns of formal and informal social capital in Europe. European Sociological Review 23(4): 425-435. 
Putnam RD (2007) E pluribus unum: Diversity and community in the twenty-first century. The 2006 Johan Skytte Prize Lecture. Scandinavian Political Studies 30(2): 137-174.

Savelkoul M, Gesthuizen M and Scheepers P (2011a) Explaining relationships between ethnic diversity and informal social capital across European countries and regions: Tests of constrict, conflict, and contact theory. Social Science Research 40(4): 1091-1107.

Savelkoul M, Scheepers P, Tolsma J and Hagendoorn L (2011b) Anti-Muslim attitudes in the Netherlands: Tests of contradictory hypotheses derived from ethnic competition theory and intergroup contact theory. European Sociological Review. Epub ahead of print 1 June 2012. doi: 10.1093/esr/jcq035.

Schlueter E and Scheepers P (2010) The relationship between outgroup size and anti-outgroup attitudes: A theoretical synthesis and empirical test of group threat- and intergroup contact theory. Social Science Research 39(2): 285-295.

Schneider SL (2008) Anti-immigrant attitudes in Europe: Outgroup size and perceived ethnic threat. European Sociological Review 24(1): 53-67.

Semyonov M, Raijman R and Gorodzeisky A (2008) Foreigners' impact on European societies: Public views and perceptions in a cross-national comparative perspective. International Journal of Comparative Sociology 49(1): 5-29.

Snijders TAB and Bosker RJ (1999) Multilevel Analysis: An Introduction to Basic and Advanced Multilevel Modelling. London: Sage.

Tolsma J, Van der Meer T and Gesthuizen M (2009) The impact of neighbourhood and municipality characteristics on social cohesion in the Netherlands. Acta Politica 44(3): 286-313.

Van der Meer T, Te Grotenhuis M and Pelzer B (2010) Influential cases in multilevel modeling. A methodological comment. American Sociological Review 75(1): 173-178.

Vervoort M, Flap H and Dagevos J (2010) The ethnic composition of the Neighbourhood and ethnic minorities' social contacts: Three unresolved issues. European Sociological Review. Epub ahead of print 1 June 2012. doi: 10.1093/esr/jcq029.

\section{Author biographies}

Tim Huijts is Assistant Professor of Sociology in the Department of Sociology/ICS, Utrecht University, The Netherlands. His main research interests include ethnic diversity, social capital, health inequality, multi-level methods, cross-national research and social mobility. He has published on these subjects in several international journals.

Gerbert Kraaykamp is Professor in Empirical Sociology in the Department of Sociology/ICS, Radboud University Nijmegen, The Netherlands. His major research interests include educational inequality, cultural capital and health inequality. He has published widely on these subjects in international journals.

Peer Scheepers is Professor of Comparative Methodology in the Department of Sociology/ICS, Radboud University Nijmegen, The Netherlands. He is also a Scientific Director of Research in the Societal Sciences and an elected member of the Royal Dutch Academy of Sciences. His research interests include (cross-national) studies in attitudes and behaviour regarding exclusion of out-groups and support for and solidarity with in-groups on which he has extensively published in international journals. 